\title{
Effect of Somatic Mutation on DNA Binding Properties of Anti-DNA Autoantihodiles
}

\author{
Melissa J. Bobeck, ${ }^{1}$ Joanne Cleary, ${ }^{1}$ Jenny A. Beckingham, ${ }^{1}$ P. Christine Ackroyd, ${ }^{1}$ Gary D. Glick ${ }^{1,2}$ \\ ${ }^{1}$ Department of Chemistry, University of Michigan, Ann Arbor, MI 48109-1055 \\ ${ }^{2}$ Department of Biological Chemistry, University of Michigan, Ann Arbor, MI 48109-1055
}

Received 6 January 2007; accepted 22 January 2007

Published online 24 January 2007 in Wiley InterScience (www.interscience.wiley.com). DOI 10.1002/bip.20691

\section{ABSTRACT:}

Autoantibodies that bind DNA are a hallmark of systemic lupus erythematosus. A subset of autoantibody•DNA complexes localize to kidney tissue and lead to damage and even death. $11 \mathrm{~F} 8,9 \mathrm{~F} 11$, and $15 \mathrm{~B} 10$ are clonally related anti-DNA autoantibodies isolated from an autoimmune mouse. 11F8 binds ssDNA in a sequencespecific manner and causes tissue damage, while $9 F 11$ and $15 B 10$ bind ssDNA non-specifically and are benign. Among these antibodies, DNA binding properties are mediated by five amino acid differences in primary sequence. Thermodynamic and kinetic parameters associated with recognition of structurally different DNA sequences were determined for each antibody to provide insight toward recognition strategies, and to explore a link between binding properties and disease pathogenesis. A model of $11 \mathrm{~F} 8$ bound to its high affinity consensus sequence provides a foundation for understanding the differences in thermodynamic and kinetic parameters between the three $m A b s$. Our data suggest that $11 \mathrm{~F} 8$ utilizes the proposed ssDNA recognition motif including ${ }^{Y 32} V_{L}$, a hydrogen bonding residue at ${ }^{91} V_{L}$, and an

Correspondence to: Gary D. Glick; e-mail: gglick@umich.edu Contract grant sponsor: National Institutes of Health Contract grant number: GM 46831

Contract grant sponsor: Chemistry Biology Interface Training Grant This article contains supplementary material available via the Internet at http:// www.interscience.wiley.com/jpages/0006-3525/suppmat

\section{(2) WILEY \\ InterScience}

(ㅇ) 2007 Wiley Periodicals, Inc. aromatic residue at the tip of the third heavy chain complementarity determining region. Interestingly, a somatic mutation to arginine at ${ }^{31} V_{H}$ in $11 F 8$ may afford additional binding site contacts including ${ }^{R 31} V_{H},{ }^{R 96} V_{H}$, and ${ }^{R 98} V_{H}$ that could determine specificity. (C) 2007 Wiley Periodicals, Inc. Biopolymers 85: 471-480, 2007.

Keywords: sequence specific recognition of single-stranded DNA; somatic mutation; lupus

This article was originally published online as an accepted preprint. The "Published Online" date corresponds to the preprint version. You can request a copy of the preprint by emailing the Biopolymers editorial office at biopolymers@wiley.com

\section{INTRODUCTION}

ystemic lupus erythematosus is an autoimmune disease characterized by antibodies that bind a wide range of nuclear and cellular antigens, including DNA. ${ }^{1}$ Increased serum anti-DNA autoantibody (anti-DNA) levels often correlate with disease activity. ${ }^{2,3}$ Some anti-DNA localize to the glomerular basement membrane by binding DNA adherent to the membrane that results in renal damage. ${ }^{4-7}$ Given the key role of antigen recognition, the binding properties of anti-DNA monoclonal antibodies (mAbs) have been extensively studied. ${ }^{8-12}$ These investigations are predicated on the assumption that understanding anti-DNA recognition would enable meaningful predictions of disease severity, provide a means to differentiate pathogenic from nonpathogenic mAbs, and even highlight strategies for interference to prevent formation of pathogenic complexes. Despite considerable effort, a cogent link between DNA recognition and disease pathogenesis is yet to be established. Previously, we generated a panel of anti-DNA from an MRL lupus prone mouse (MRL/lpr) to probe for 


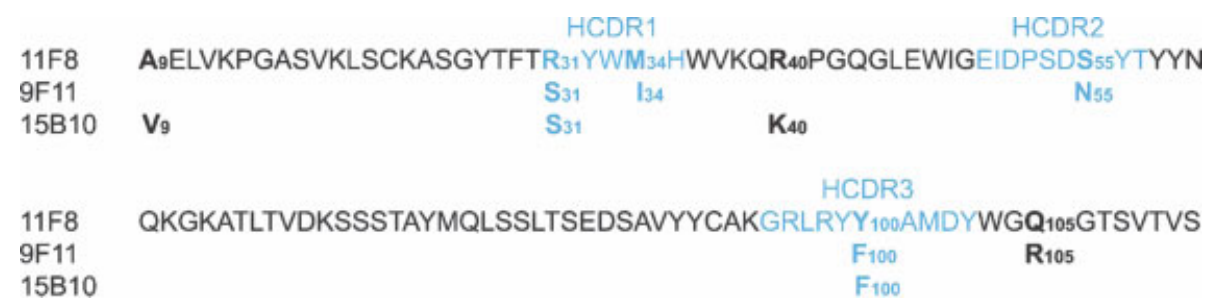

FIGURE 1 Sequence alignment of the heavy chain variable residues for clonally related mAbs 11F8, 9F11, and 15B10. Sequence differences are localized to the heavy chain. Complementarity determining regions are colored blue and mutations resulting from somatic hypermutation are noted in bold. Sequences are numbered according to Kabat et al. ${ }^{18}$

links between binding properties and pathogenesis. ${ }^{13,14}$ Two mAbs 9F11 and 15B10 showed preference for oligo thymine, but only one mAb, 11F8, was sequence-specific. ${ }^{15}$ Administration of $11 \mathrm{~F} 8,9 \mathrm{~F} 11$, and $15 \mathrm{~B} 10$ to normal mice revealed that only $11 \mathrm{~F} 8$ was pathogenic. ${ }^{13}$

Somatic hypermutation is a process that occurs in $\mathrm{mAb}$ genes during affinity maturation, where localized mutations can profoundly affect antigen binding. ${ }^{16,17}$ Remarkably, the primary sequence of 11F8, 9F11, and 15B10 differs by five or less amino acids, and these differences are localized to the variable region of the heavy chain $\left(\mathrm{V}_{\mathrm{H}}\right)$ (Figure 1). Two binding site residues, ${ }^{\mathrm{R} 31} \mathrm{~V}_{\mathrm{H}}$ and ${ }^{\mathrm{Y} 100} \mathrm{~V}_{\mathrm{H}}$, which have been shown to mediate sequence-specificity in $11 \mathrm{~F} 8$, were acquired during affinity maturation, and they are unmutated in both 9F11 and 15B10. ${ }^{19,20}$ Since DNA binding properties are inherent to primary sequence, $11 \mathrm{~F} 8,9 \mathrm{~F} 11$, and $15 \mathrm{~B} 10$ provide an attractive model system to compare and contrast DNA binding properties of anti-DNA with distinct biological properties. In these studies, the binding properties of 9F11 and $15 \mathrm{~B} 10$ to different DNA sequences: 11F8 high affinity consensus sequence, (1), oligo thymine (T7), and a nonspecific ssDNA ligand (NS), were determined and compared with $11 \mathrm{~F} 8$ (Figure 2). ${ }^{20-22}$ Two $11 \mathrm{~F} 8$ reversion mutants, ${ }^{\mathrm{R} 31 \mathrm{~S}} \mathrm{~V}_{\mathrm{H}}$ and ${ }^{\mathrm{Y} 100 \mathrm{~F}} \mathrm{~V}_{\mathrm{H}}$, were constructed to mimic residues present in 9F11 and 15B10. Thermodynamic and kinetic studies of the reversion mutants supported the hypothesis that ${ }^{\mathrm{R} 31} \mathrm{~V}_{\mathrm{H}}$ is primarily responsible for the differences observed between 11F8, 9F11, and 15B10. Our data support a model where pathogenic anti-DNA arise at the level of somatic mutation during affinity maturation. Somatic mutation to certain amino acids such as arginine or at specific variable region positions may be a feature that distinguishes pathogenic anti-DNA from those that are benign.

\section{MATERIALS AND METHODS}

\section{Protein Preparations}

Intact 11F8, 9F11, and 15B10 were isolated from ascities fluid and purified by affinity chromatography $(>95 \%)$ as previously de- scribed. ${ }^{14}$ Antibody concentrations were calculated from the $A_{280}$ with an extinction coefficient $\left(0.67 \mathrm{mg} \mathrm{ml} \mathrm{m}^{-1} / \mathrm{OD}_{280}\right)$ calculated from the amino acid sequence. ${ }^{23}$

Determination of the thermodynamic parameters and rate constants for reversion mutants required recombinant expression of the single-chain $11 \mathrm{~F} 8$ variable region. ${ }^{20} 11 \mathrm{~F} 8$ was cloned into the pET$28 \mathrm{~b}(+)$ vector (Novagen, Madison, WI), and 11F8 reversion mutants ${ }^{\mathrm{R} 31 \mathrm{~S}} \mathrm{~V}_{\mathrm{H}}$ (arginine to serine mutation at position 31 of the heavy chain variable region), ${ }^{\mathrm{Y} 100 \mathrm{~F}} \mathrm{~V}_{\mathrm{H}}$, and ${ }^{\mathrm{R} 31 \mathrm{~S}, \mathrm{Y} 100 \mathrm{~F}} \mathrm{~V}_{\mathrm{H}}$ were constructed using Quickchange Site-Directed Mutagenesis Kit (Stratagene, La Jolla, CA). The mutant proteins were expressed, purified, and quantified as described for wild-type $11 \mathrm{~F} 8 .^{20}$ The stability of each mutant was verified through guanidine unfolding and compared with the wild-type $11 \mathrm{~F}^{20}{ }^{20}$ Proteins were purified to $>98 \%$ as judged by gel electrophoresis for thermodynamic and kinetic studies.

\section{Steady-State Fluorescence Affinity Measurements}

DNA sequences were synthesized, purified to $\geqslant 95 \%$ by HPLC, and quantified as previously described. ${ }^{15,21}$ Fluorescence measurements were carried out on a Spectronic AB2 fluorimeter with magnetic

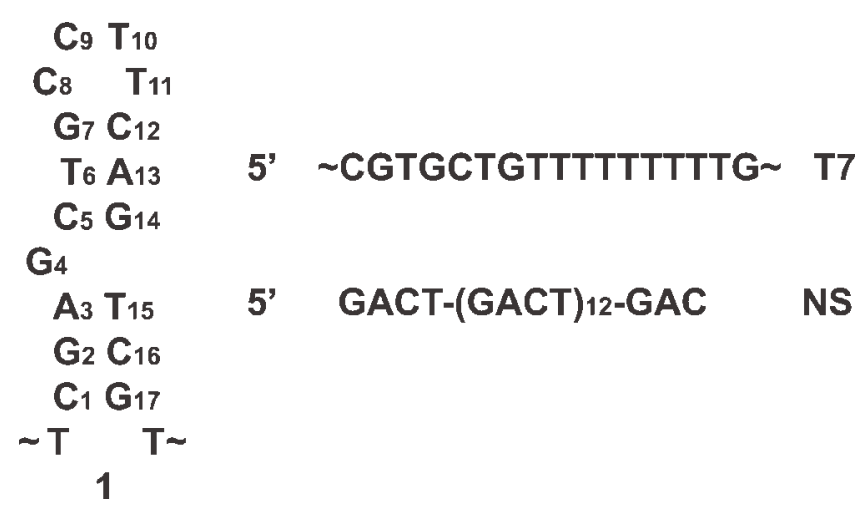

FIGURE 2 Sequence of ssDNA ligands used in binding studies. 1 is the high affinity sequence for $11 \mathrm{~F} 8 .{ }^{15}$ Nucleotides that functioned as PCR primers during selection but do not participate in recognition are not shown $(\sim)$. In the thymine rich sequence, T7, positions $3,8-14$, and 16 of 1 are replaced with thymine to remove structural and recognition elements. All bases are represented equally in NS, which adopts no secondary structure. Ligands used in thermodynamic studies are 55 nucleotides long. Kinetic studies were completed with a 19 nucleotide truncated hairpin that removed PCR primers. Truncation does not decrease binding affinity. ${ }^{22}$ 
stirrer and thermostated cellblock. ${ }^{21}$ Briefly, antibody was diluted into titration buffer (20 $\mathrm{mM}$ Tris, $150 \mathrm{mM} \mathrm{NaCl}, \mathrm{pH}$ 8.0) and allowed to equilibrate at $25^{\circ} \mathrm{C}$. The quench in intrinsic tryptophan fluorescence was monitored as a function of added DNA and fit to the single-site binding isotherm to obtain the dissociation constant. ${ }^{21}$ Thermodynamic parameters were determined as previously described. $^{21}$

\section{Stopped-Flow Measurements}

Stopped-flow measurements were conducted using a $\pi^{*}$-CDF stopped-flow spectrophotometer from Applied Photophysics (Surrey, UK). The apparent association $\left(k_{\mathrm{on}}\right)$ and dissociation $\left(k_{\mathrm{off}}\right)$ rate constants were determined as previously described. ${ }^{22,24}$ Briefly, the excitation wavelengths were the same as used for equilibrium experiments and the emission was monitored with suitable cutoff filters. All measurements were performed in $20 \mathrm{mM}$ Tris- $\mathrm{HCl}, \mathrm{pH}$ 8.0, $100 \mathrm{mM} \mathrm{NaCl}, 20 \% \mathrm{w} / \mathrm{v}$ sucrose at $5^{\circ} \mathrm{C}$. Because initial signal changes observed on binding were rapid, occurring within the deadtime of the instrument, $20 \%$ sucrose was added to increase buffer viscosity, and temperature was lowered to $5^{\circ} \mathrm{C}$ to decrease the rate of association such that the quench upon binding was observed completely with respect to initial protein fluorescence. Each experiment was carried out at least eight times and analyzed both individually and as an average by single or double exponential curve fitting algorithms using the software supplied with the instrument.

In experiments to determine the association rates for complex formation, $[\mathrm{mAb}]$ prior to mixing (100 $\mathrm{nM}$ for whole mAbs containing two antigen binding sites or $200 \mathrm{nM}$ for single-chain 11F8 varaints containing a single binding site) was kept constant while the DNA was maintained in at least a 10-fold excess to approximate pseudo-first-order reactions conditions. From the plot of [DNA] versus $k_{\text {app }}$, the apparent second-order rate constants, $k_{\text {on }}$, were calculated from the slope, and the dissociation of the complex, $k_{\text {off }}$, was calculated from the $y$-intercept. Because of the high affinity of the complex, dissociation experiments were carried out by mixing a preformed complex $(11 \mathrm{~F} 8 \bullet 1 \mathrm{AP})$ with 10 -fold excess of $1(1: 1 \mathrm{v} / \mathrm{v})$ as previously reported. ${ }^{22}$ The fluorescence of amino purine was monitored as the complex dissociated.

\section{RESULTS}

\section{Selection of DNA Sequences for Thermodynamic and Kinetic Studies}

Single-stranded DNA binding properties were determined for three clonally-related mAbs to evaluate whether differences in thermodynamic and kinetic parameters for recognition of ssDNA exist, and to establish if these differences relate to pathogenicity. Three DNA sequences were chosen for evaluation of binding parameters. 1 is the high affinity consensus sequence for 11F8 identified in binding site selection experiments. ${ }^{15}$ Prior studies show that $11 \mathrm{~F} 8$ binds this ligand sequence specifically. ${ }^{20}$ Many ssDNA-binding proteins, including 11F8, 9F11, and 15B10, display a base preference for thymine, and affinity for oligo thymine was analyzed for noncognate binding. ${ }^{14,25-30} \mathrm{~T} 7$ was chosen to examine recognition of this homopolymer within the same context as $\mathbf{1}$. NS is a nonspecific ligand that represents all bases equally, and like T7 does not possess secondary structure.

\section{Comparison of Thermodynamic Parameters for mAb•1 Recognition}

To determine the enthalpic and entropic driving force for $\mathrm{mAb}$ recognition of different ssDNA ligands, affinity measurements were conducted as a function of temperature. Data were plotted in van't Hoff form (ln $K_{\text {obs }}$ vs. $1 / \mathrm{T}$ ) and analyzed assuming either zero or constant negative heat capacity based on either linear or nonlinear dependence of affinity on temperature, respectively. ${ }^{31-33}$ The limitations of this analysis are discussed in a recent review, and representative van't Hoff plots are included as supplementary information. ${ }^{34}$ 11F8 binds 1 seven-fold tighter than $9 \mathrm{~F} 11$ and $15 \mathrm{~B} 10$ (Table I). Lower affinity may reflect either the absence of specific contacts as compared with the $11 \mathrm{~F} 8 \bullet 1$ complex or a different mode of binding. Thermodynamic parameters for recognition of 1 were determined for $9 \mathrm{~F} 11$ and $15 \mathrm{~B} 10$ by measuring binding affinity as a function of temperature $(\mathrm{Ta}-$ ble I). Similar to $11 \mathrm{~F} 8$, recognition of 1 by $9 \mathrm{~F} 11$ and $15 \mathrm{~B} 10$ is enthalpically favorable and opposed by entropy. The thermodynamic parameters for $9 \mathrm{~F} 11 \bullet 1$ and $15 \mathrm{~B} 10 \bullet 1$ are within error of $11 \mathrm{~F} 8 \bullet 1$ values, and uncertainties in enthalpy and entropy values render them indistinguishable from $11 \mathrm{~F} 8$. From thermodynamic parameters alone, it is not possible to ascribe the source of the weaker affinities of 9F11 and 15B10 for $\mathbf{1}$ to processes that are either primarily entropic or enthalpic. The nonclassical hydrophobic effect is the largest contributor to the favorable enthalpy observed for $11 \mathrm{~F} 8 \mathrm{rec}-$ ognition of $1 .^{21}$ To determine whether the net enthalpy changes associated with $9 \mathrm{~F} 11$ and $15 \mathrm{~B} 10$ recognition of 1 reflect similar processes, binding affinity was determined as a function of buffer polarity (glycerol and 1-propanol). Decrease in solution polarity weakens binding similarly in all three mAbs, which suggests in all cases, the hydrophobic effect provides a significant driving force for recognition (data not shown).

One of the sequence differences between 11F8 and both 9F11 and $15 \mathrm{~B} 10$ is found at ${ }^{31} \mathrm{~V}_{\mathrm{H}}$. $9 \mathrm{~F} 11$ and $15 \mathrm{~B} 10$ have a germline serine while somatic hypermutation in $11 \mathrm{~F} 8$ affords arginine. ${ }^{19}$ Mutagenesis and structural studies suggest that ${ }^{\mathrm{R} 31} \mathrm{~V}_{\mathrm{H}}$ at the periphery of the binding site contacts 1 through both salt bridge and specific base contacts. ${ }^{20,24,35}$ A binding site serine in place of arginine means loss of positive charge at the interface, eliminating potential hydrogen bond and electrostatic contacts with the DNA backbone. While direct side chain-base contacts could only be assessed through 
Table I Thermodynamic Parameters for mAb•1 Complexes

\begin{tabular}{llccccc}
\hline mAb & $\begin{array}{l}K_{\mathrm{d}} \\
(\mathrm{nM})^{\mathrm{a}}\end{array}$ & $\begin{array}{c}\Delta G \\
\left(\mathrm{kcal} \mathrm{mol}^{-1}\right)^{\mathrm{b}}\end{array}$ & $\begin{array}{c}\Delta H \\
\left(\mathrm{kcal} \mathrm{mol}^{-1}\right)^{\mathrm{b}}\end{array}$ & $\begin{array}{c}T \Delta S \\
\left(\mathrm{kcal} \mathrm{mol}^{-1}\right)^{\mathrm{b}}\end{array}$ & $-S K_{\mathrm{obs}}{ }^{\mathrm{c}}$ & $\begin{array}{c}\Delta G_{\text {elect }} \\
\left(\mathrm{kcal} \mathrm{mol}^{-1}\right)^{\mathrm{d}}\end{array}$ \\
\hline $11 \mathrm{~F} 8$ & $10 \pm 1$ & $-10.9 \pm 0.1$ & $-22 \pm 2$ & $-11 \pm 2$ & $2.2 \pm 0.1$ & $-2.5 \pm 0.1$ \\
9F11 & $69 \pm 17$ & $-9.8 \pm 0.2$ & $-23 \pm 1$ & $-13 \pm 1$ & $1.0 \pm 0.1$ & $-1.1 \pm 0.1$ \\
$15 \mathrm{~B} 10$ & $72 \pm 8$ & $-9.8 \pm 0.1$ & $-24 \pm 2$ & $-14 \pm 2$ & $1.3 \pm 0.1$ & $-1.4 \pm 0.1$ \\
\hline
\end{tabular}

11F8 data are included for reference. 11F8 thermodynamic parameters were estimated by assuming a constant negative heat capacity due to curvature in the van't Hoff plot. ${ }^{21}$ Errors for $K_{\mathrm{d}}$ and $\Delta G$ are the standard deviations of at least three independent assays. Errors reported for $\Delta H, T \Delta S,-S K_{\mathrm{obs}}$, and $\Delta G_{\text {elect }}$ reflect either uncertainty associated with nonlinear least-squares regression or the standard deviation of the slope of the linear van't Hoff plot as previously described. ${ }^{21}$

${ }^{a}$ Affinity data were measured in $20 \mathrm{mM}$ Tris, $150 \mathrm{mM} \mathrm{NaCl}, \mathrm{pH} 8.0$ at $25^{\circ} \mathrm{C}$.

${ }^{\mathrm{b}}$ The change in affinity with respect to temperature measured from 5 to $35^{\circ} \mathrm{C}$ was used to determine thermodynamic parameters for $9 \mathrm{~F} 11$ and $15 \mathrm{~B} 10$ assuming a zero heat capacity change due to linearity of the van't Hoff plot (ln $K_{\mathrm{d}}$ vs. $\left.1 / T\right)$.

${ }^{c}$ Values of $-S K_{\text {obs }}$ represent the stoichiometry of salt release determined at $25^{\circ} \mathrm{C}$ with buffer salt concentrations ranging from $85-300 \mathrm{mM}$ as described by Record. ${ }^{31}$

${ }^{\mathrm{d}}$ The energetic contribution of salt release $\left(\Delta G_{\text {elect }}\right)$ at $150 \mathrm{mM} \mathrm{NaCl}$ was calculated as described by Record. ${ }^{32}$

double mutant studies, a change in the number of putative salt bridge interactions would be evident from the stoichiometry of cation release accompanying complex formation. ${ }^{31}$ Reduction in salt bridge formation could alter the thermodynamic impact of the polyelectrolyte effect, which contributes to binding through a favorable entropy change.

To measure salt release upon complex formation, mAb•1 affinity was determined as a function of buffer salt concentration. As shown in Table I, stoichiometries of salt release for $9 \mathrm{~F} 11 \bullet 1$ and $15 \mathrm{~B} 10 \bullet 1$ suggest only one salt bridge in these complexes, while $11 \mathrm{~F} 8 \bullet 1$ has two. This change translates a reduced energetic contribution of the polyelectrolyte effect, from $\sim 22 \%$ of the total binding energy for $11 \mathrm{~F} 8 \bullet 1$ to roughly half that amount in the 9F11 and 15B10 complexes. Thus, the weaker affinity of $9 \mathrm{~F} 11$ and $15 \mathrm{~B} 10$ for 1 could result exclusively from the entropic impact of salt bridge reduction in the absence of a binding site arginine.

\section{Comparison of Thermodynamic Parameters for mAb•NS Recognition}

The polyelectrolyte effect drives nonspecific recognition of ssDNA by $11 \mathrm{~F} 8 .{ }^{21}$ Shift in driving force from the nonclassical hydrophobic effect for sequence-specific recognition of 1 to the polyelectrolyte effect reflects the ability of 11F8 to adapt its mode of binding to achieve the most favorable set of contacts with the available DNA ligand. The affinity of $11 \mathrm{~F} 8$ for NS DNA is greater than fivefold tighter than the affinity of 9F11 and 15B10 for the same sequence (Table II). Thermodynamic parameters accompanying $9 \mathrm{~F} 11 \bullet \mathrm{NS}$ and $15 \mathrm{~B} 10 \bullet \mathrm{NS}$ complex formation suggest that recognition of NS is driven by favorable enthalpy change and opposed by entropy, and that these mAbs do not utilize the polyelectrolyte effect to the same extent as 11F8 (Table II). For 11F8•NS, the estimated contribution of cation release is $-10.0 \mathrm{kcal} \mathrm{mol}^{-1}$, which is $>100 \%$ of the observed binding energy. This analysis

Table II Thermodynamic Parameters for mAb•NS Complexes

\begin{tabular}{|c|c|c|c|c|c|c|}
\hline $\mathrm{mAb}$ & $\begin{array}{l}K_{\mathrm{d}} \\
(\mu M)^{\mathrm{a}}\end{array}$ & $\begin{array}{c}\Delta G \\
\left(\mathrm{kcal} \mathrm{mol}^{-1}\right)^{\mathrm{b}}\end{array}$ & $\begin{array}{c}\Delta H \\
\left(\mathrm{kcal} \mathrm{mol}^{-1}\right)^{\mathrm{b}}\end{array}$ & $\begin{array}{c}T \Delta S \\
\left(\mathrm{kcal} \mathrm{mol}^{-1}\right)^{\mathrm{b}}\end{array}$ & $-S K_{\mathrm{obs}}{ }^{\mathrm{c}}$ & $\begin{array}{c}\Delta G_{\text {elect }} \\
\left(\mathrm{kcal} \mathrm{mol}^{-1}\right)^{\mathrm{c}}\end{array}$ \\
\hline $11 \mathrm{~F} 8$ & $0.4 \pm 0.1$ & $-8.8 \pm 0.1$ & 0 & $8.8 \pm 0.1$ & $7.3 \pm 0.1$ & $-10.0 \pm 0.1$ \\
\hline 9F11 & $2.2 \pm 0.4$ & $-7.7 \pm 1.1$ & $-11.6 \pm 0.5$ & $-3.9 \pm 0.9$ & $3.2 \pm 0.1$ & $-4.3 \pm 0.1$ \\
\hline $15 B 10$ & $5.0 \pm 1.0$ & $-7.2 \pm 0.8$ & $-15.0 \pm 13$ & $-8.0 \pm 7.0$ & $3.2 \pm 0.1$ & $-4.4 \pm 0.1$ \\
\hline
\end{tabular}

Refer to Table I for footnote definitions except for the following modifications. 11F8 data are included for reference. 11F8 thermodynamic parameters were estimated by assuming a zero heat capacity change due to linearity of the van't Hoff plot. ${ }^{21}$

${ }^{\text {a }}$ Affinity data were measured in $20 \mathrm{mM}$ Tris, $100 \mathrm{mM} \mathrm{NaCl}, \mathrm{pH} 8.0$ at $25^{\circ} \mathrm{C}$.

${ }^{\mathrm{b}}$ Thermodynamic parameters for $9 \mathrm{~F} 11$ and 15B10 were determined assuming a constant negative heat capacity suggested by curvature in the van't Hoff plot $\left(\ln K_{\mathrm{d}}\right.$ vs. $\left.1 / T\right)$.

${ }^{\mathrm{c}}$ The stochiometry of salt release was determined with buffer salt concentrations ranging from $85-150 \mathrm{mM}$. 
Table III Thermodynamic Parameters for mAb•T7 Complexes

\begin{tabular}{lcccccc}
\hline & $\begin{array}{c}K_{\mathrm{d}} \\
\mathrm{mAb}\end{array}$ & $\begin{array}{c}\Delta G \\
(\mathrm{nM})^{\mathrm{a}}\end{array}$ & $\begin{array}{c}\Delta H \\
\left(\mathrm{kcal} \mathrm{mol}^{-1}\right)^{\mathrm{b}}\end{array}$ & $\begin{array}{c}T \Delta S \\
\left(\mathrm{kcal} \mathrm{mol}^{-1}\right)^{\mathrm{b}}\end{array}$ & $-S K_{\mathrm{obs}}{ }^{\mathrm{c}}$ & $\begin{array}{c}\Delta G_{\text {elect }} \\
\left(\mathrm{kcal} \mathrm{mol}^{-1}\right)^{\mathrm{d}}\end{array}$ \\
\hline $11 \mathrm{~F} 8$ & $1400 \pm 200$ & $-8.0 \pm 0.1$ & $-28.7 \pm 0.6$ & $-20.7 \pm 0.6$ & $3.4 \pm 0.1$ & $-1.6 \pm 0.1$ \\
9F11 & $160 \pm 30$ & $-10.1 \pm 0.1$ & $-25.8 \pm 0.9$ & $-15.7 \pm 0.9$ & $2.3 \pm 0.2$ & $-1.1 \pm 0.2$ \\
$15 \mathrm{~B} 10$ & $42 \pm 4$ & $-9.3 \pm 0.1$ & $-24.2 \pm 0.8$ & $-14.9 \pm 0.8$ & $2.1 \pm 0.1$ & $-1.0 \pm 0.1$ \\
\hline
\end{tabular}

Refer to Table I for footnote definitions except for the following modifications. 11F8 data are included for reference. 11F8 thermodynamic parameters were estimated by assuming a zero heat capacity change due to linearity of the van't Hoff plot. ${ }^{21}$

${ }^{\text {a }}$ Affinity data were measured in $20 \mathrm{mM}$ Tris, $450 \mathrm{mM} \mathrm{NaCl}$, pH 8.0 at $25^{\circ} \mathrm{C}$.

${ }^{\mathrm{b}}$ The stochiometry of salt release was determined with buffer salt concentrations ranging from $100-450 \mathrm{mM}$.

suggests that the polyelectrolyte effect may be the sole driving force for nonspecific ssDNA recognition by $11 \mathrm{~F} 8$, while the polyelectrolyte effect contributes only $\sim 60 \%$ of the total free energy for the 9F11•NS and 15B10•NS complexes.

Previous studies have suggested that pathogenic antiDNA may be more basic in nature than nonpathogenic $\mathrm{mAbs}$ since the isoelectric points ( $\mathrm{pI}$ ) for mAbs isolated form kidney tissue are more basic than serum antibodies, ranging between 7.2 and 9.2. ${ }^{36}$ The pIs for the variable regions of $11 \mathrm{~F} 8,9 \mathrm{~F} 11$, and $15 \mathrm{~B} 10$ are basic at 8.9, 8.9, and 8.7, respectively; however, 9F11 and $15 \mathrm{~B} 10$ are not pathogenic. Sequence comparison for variable regions reveal identical light chains, and heavy chains containing a similar number of charged side chains ( 13 positive and 9 negative side chains in $11 \mathrm{~F} 8$ and 9F11, and 12 positive and 9 negative side chains in 15B10). Thus, differences in affinity and mode of binding likely result from the absence of a specific cationic arginine at the DNA binding site of $9 \mathrm{~F} 11$ and $15 \mathrm{~B} 10$ rather than sequence differences in the variable region. ${ }^{37}$

\section{Comparison of Thermodynamic Parameters for mAb•T7 Recognition}

9F11 and 15B10 bind T7 with higher affinity than 11F8 (Table III). Since these mAbs bind NS with lower affinity than $11 \mathrm{~F} 8$, higher affinity for $\mathrm{T} 7$ reflects increased preference for thymine-rich sequences rather than simply increased affinity for DNA. The thermodynamic parameters accompanying 9F11 and 15B10 recognition of T7 were determined to identify the driving force for thymine base preference. As for $11 \mathrm{~F} 8$, recognition of $\mathrm{T} 7$ by $9 \mathrm{~F} 11$ and $15 \mathrm{~B} 10$ is driven by a favorable enthalpy change and opposed by entropy. Both enthalpy and entropy changes for 9F11 and 15B10 recognition of T7 are smaller than for 11F8 indicating that complex formation is less enthalpically favored and less entropically disfavored. These data suggest that the higher affinities of 9F11 and 15B10 for T7 could be a consequence of smaller entropic costs associated with binding. Increases in salt release for 9F11•T7 and 15B10•T7 complexes could contribute to the smaller unfavorable entropy change observed. However, salt release stoichiometries are smaller than those observed for $11 \mathrm{~F} 8$, as are the thermodynamic contributions of the polyelectrolyte effect (Table III). Hence, an increased salt release is not the source of the more favorable entropy change observed for 9F11•T7 and 15B10•T7.

Increased affinity of $9 \mathrm{~F} 11$ and $15 \mathrm{~B} 10$ for $\mathrm{T} 7$ relative to $11 \mathrm{~F} 8$ could also result from increased involvement of the hydrophobic effect; however, the sensitivity of 9F11 and 15B10 affinity for T7 was affected by bulk solution polarity to the same extent as $11 \mathrm{~F} 8 \bullet \mathrm{T} 7$ suggesting similar involvement of the hydrophobic effect (data not shown). ${ }^{21}$ Protein॰DNA interactions depend strongly on the contacts available, and a single protein may bind two different DNA sequences in different modes, with different interface contacts. $^{38}$ Nonspecific recognition of DNA is typically dominated by electrostatic interactions showing stronger salt concentration dependence than corresponding specific binding. ${ }^{33,39,40}$ When $11 \mathrm{~F} 8$ binds NS, the recognition mode shifts from enthalpically driven to entropically driven and the electrostatic component of the binding energy increases from $\sim 20 \%$ in sequence-specific binding to $100 \%$ in nonspecific binding. However, both $9 \mathrm{~F} 11$ and 15B10 recognition of NS remains enthalpically favorable, suggesting that electrostatic contacts play far less a role in DNA binding. We hypothesize that $9 \mathrm{~F} 11$ and $15 \mathrm{~B} 10$ have an inherent propensity to accommodate two thymine nucleotides. Because thymine nucleotides could bind nondiscriminatorily in many different registers along the ssDNA ligand, such accommodation could explain the high affinity for T7.

\section{Kinetics of $\mathrm{mAb}$ Binding to 1}

To probe if differences in the kinetics of DNA recognition exist for 11F8, 9F11, and 15B10, association and dissociation 

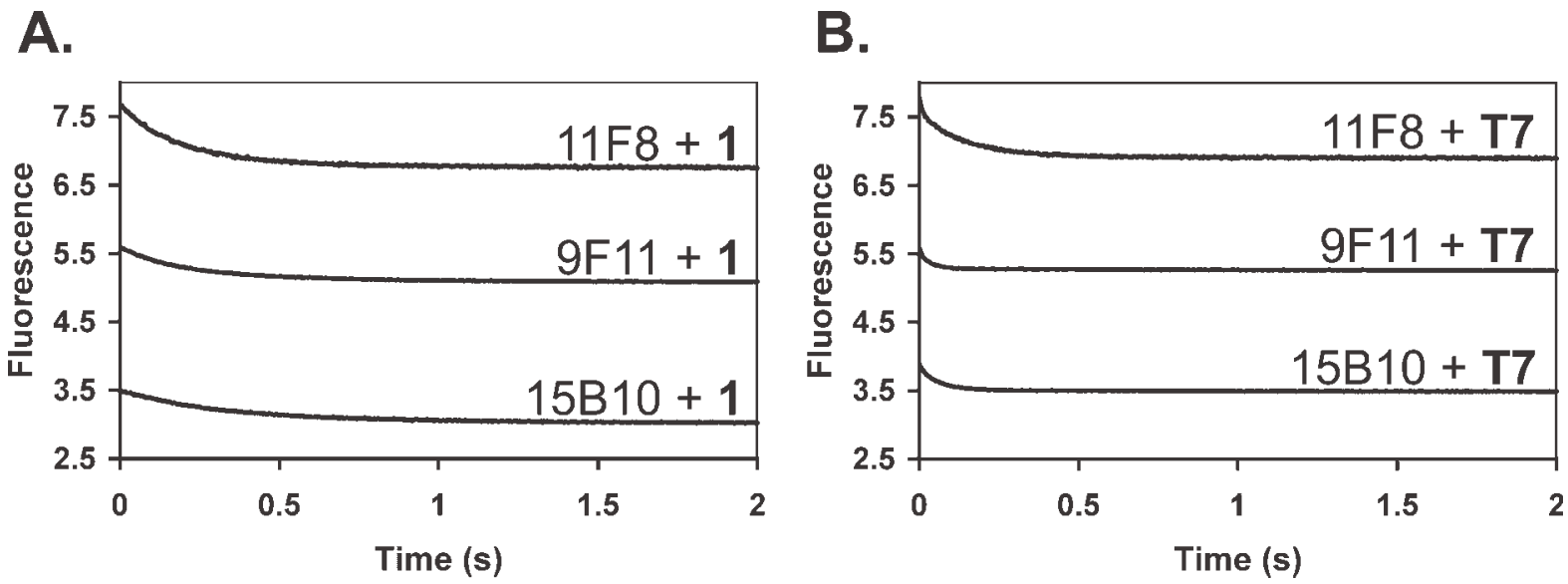

FIGURE 3 Representative stopped-flow fluorescence traces for the interaction between 11F8 and ssDNA in $20 \mathrm{mM}$ Tris, $100 \mathrm{mM} \mathrm{NaCl}, \mathrm{pH} 8.0,20 \%$ w/v sucrose at $5^{\circ} \mathrm{C}$. A: Double exponential association traces for the interaction between $1(2 \mu M)$ and 11F8 $(100 \mathrm{nM})$ and single exponential traces for the interaction between 1 and 9F11 and 15B10. Buffer viscosity was increased and temperature was decreased such that the binding event did not occur within the dead time of the instrument. B: Double exponential association traces for the interaction between T7 $(2 \mu M)$ and mAbs $(100 \mathrm{nM})$. Fluorescence traces are artificially scaled so that spectra do not overlap.

rate constants were measured for each antibody with 1 and T7. The kinetic parameters for recognition of NS were not completed because affinity differences were sufficiently explained by thermodynamic parameters alone. DNA binding is accompanied by a $40 \%$ quench in tryptophan fluorescence for all three mAbs. Exponential fit of the decrease in tryptophan fluorescence was used to determine kinetic rate constants for recognition of ssDNA. ${ }^{22,24} 11 \mathrm{~F} 8 \bullet 1$ complex formation occurs in two steps as evidenced by a double exponential decay in tryptophan fluorescence. An initial encounter complex is formed, followed by a slower rate-limiting conformational change that results in the high affinity complex. $^{22}$ Unlike 11F8, a single exponential curve fits the decrease in fluorescence observed for $9 \mathrm{~F} 11$ and 15B10 recog- nition of 1 (Figure 3A). For 9F11 and 15B10, the single observed rate is slow and independent of [1] similar to the second step in $11 \mathrm{~F} 8 \bullet 1$ association (Table IV).

We expected that the rate of encounter complex formation would decrease with one less arginine at the binding site of 9F11 and 15B10 since association is directly related to the magnitude of electrostatic forces between two interacting surfaces. ${ }^{41,42}$ However, the observation of a single rate that is independent of [DNA] suggests that formation of a bimolecular encounter complex does not cause a disemable fluorescence quench under these experimental conditions. A single observed association rate for both $9 \mathrm{~F} 11 \bullet 1$ and $15 \mathrm{~B} 10 \bullet 1$ binding is consistent with rate constants for an 11F8 mutant in which four arginine side chains were removed from the

Table IV Kinetic Parameters for mAb Recognition of ssDNA Ligands 1 and T7

\begin{tabular}{|c|c|c|c|c|c|}
\hline Complex & $k_{1}\left(\mu M^{-1} s^{-1}\right)$ & $k_{-1}\left(s^{-1}\right)$ & $k_{2}\left(\mathrm{~s}^{-1}\right)$ & $k_{-2}\left(s^{-1}\right)$ & $K_{\mathrm{d}}(\mathrm{n} M)^{\mathrm{a}}$ \\
\hline $11 \mathrm{~F} 8 \bullet 1$ & $9.3 \pm 0.6$ & $3.9 \pm 0.4$ & $4.5 \pm 0.2$ & $2.5 \times 10^{-3} \pm 2 \times 10^{-5}$ & $0.3 \pm 0.2$ \\
\hline $9 \mathrm{~F} 11 \bullet 1$ & NO & $\mathrm{NO}$ & $2.4 \pm 0.4$ & $3.6 \times 10^{-3} \pm 5 \times 10^{-6}$ & $2.7 \pm 0.2$ \\
\hline $15 \mathrm{~B} 10 \bullet 1$ & NO & NO & $1.7 \pm 0.3$ & $4.2 \times 10^{-3} \pm 4 \times 10^{-5}$ & $2.8 \pm 0.4$ \\
\hline $11 \mathrm{~F} 8 \bullet \mathrm{T} 7$ & $102.5 \pm 7.2$ & $35.2 \pm 2.6$ & $4.7 \pm 0.3$ & $3.5 \times 10^{-3} \pm 1 \times 10^{-3}$ & $4.2 \pm 0.3$ \\
\hline $9 \mathrm{~F} 11 \bullet \mathrm{T} 7$ & $35.4 \pm 2.6$ & $46.9 \pm 4.3$ & $11.8 \pm 0.8$ & $6.7 \times 10^{-3} \pm 1 \times 10^{-5}$ & $0.6 \pm 0.2$ \\
\hline $15 \mathrm{~B} 10 \bullet \mathrm{T} 7$ & $44.6 \pm 5.3$ & $33.5 \pm 4.2$ & $6.7 \pm 0.2$ & $7.6 \times 10^{-3} \pm 1 \times 10^{-6}$ & $0.9 \pm 0.3$ \\
\hline
\end{tabular}

Rate constants were measured in $20 \mathrm{mM}$ Tris, $100 \mathrm{mM} \mathrm{NaCl}$, pH 8.0, 20\% w/v sucrose at $5^{\circ} \mathrm{C}$. There is one observed step for $9 \mathrm{~F} 11$ and $15 \mathrm{~B} 10$ association with $\mathbf{1}, \mathrm{NO}$ refers to not observed. Since the observed rate is independent of [1] it is related to final complex $\left(k_{2}\right)$ in $11 \mathrm{~F} 8 \bullet \mathbf{1}$ association, which is also independent of [1]. 11F8 data are reported for comparison. ${ }^{22}$ Errors are the standard deviations of at least eight independent measurements.

${ }^{a}$ Reported Equilibrium $K_{d}$ values were determined in $20 \mathrm{mM}$ Tris, $150 \mathrm{mM} \mathrm{NaCl}, \mathrm{pH} 8.0$ at $25^{\circ} \mathrm{C}$. Errors are the standard deviations of three independent assays. 
periphery of the DNA binding site. This mutant exhibited both decrease in equilibrium affinity for $\mathbf{1}$ and a single exponential fluorescence change upon binding. ${ }^{24}$ In addition to changes in the mechanism of association, both the rate of formation of the final complex, reflected by $k_{2}$, and its dissociation $\left(k_{-2}\right)$ are altered in $9 \mathrm{~F} 11$ and $15 \mathrm{~B} 10$ binding to 1 as compared with $11 \mathrm{~F} 8$. Possessing serine at ${ }^{31} \mathrm{~V}_{\mathrm{H}}, 9 \mathrm{~F} 11$ and $15 \mathrm{~B} 10$ DNA binding sites are less positive before somatic mutation, which decreases the strength of electrostatic attraction between protein and DNA.

\section{Kinetics of mAb•T7 Recognition}

Like $11 \mathrm{~F} 8$, the decrease in fluorescence observed upon the interaction of 9F11 and 15B10 with T7 fits a double exponential, and binding occurs in two steps (Figure 3B). These data suggest that recognition of $\mathbf{T} 7$ occurs through a similar mechanism as $11 \mathrm{~F} 8 \bullet 1$, where induced-fit formation of the final complex is rate-limited by a slow conformational change described by $k_{2}$. Both association and dissociation rates describing 9F11 and 15B10 recognition of T7 differ as compared with $11 \mathrm{~F} 8$, and these differences, particularly in $k_{2}$, may help to explain the differences observed in affinity at equilibrium. The effects of the individual association and dissociation rate differences with respect to $11 \mathrm{~F} 8$ for all but $k_{2}$ (decreased rate of association to form the encounter complex, $k_{1}$, increased rate for dissociation of the encounter complex, $k_{-1}$, and increased rate for dissociation of the final complex, $k_{-2}$ ) would have a net decrease on equilibrium affinity. However, we observe increased affinity between 9F11 and $15 \mathrm{~B} 10$ for $\mathrm{T} 7$, which could result from the increased rate of formation of the high affinity complex $\left(k_{2}\right)$ possibly because of decreases in the activation energy for the rate-limiting second step (Table IV).

\section{Reversion Mutation of 11F8 to Germline}

The sequence of 11F8 differs in the same way from both 9F11 and $15 \mathrm{~B} 10$ at only two positions, ${ }^{31} \mathrm{~V}_{\mathrm{H}}$ and ${ }^{100} \mathrm{~V}_{\mathrm{H}}$. Previous studies have determined that ${ }^{\mathrm{R} 31} \mathrm{~V}_{\mathrm{H}}$ and ${ }^{\mathrm{Y} 100} \mathrm{~V}_{\mathrm{H}}$ mediate sequence-specificity in the $11 \mathrm{~F} 8 \bullet 1$ complex. ${ }^{20}$ Based on thermodynamic, kinetic, and structural studies, we hypothesize that ${ }^{\mathrm{R} 31} \mathrm{~V}_{\mathrm{H}}$ and ${ }^{\mathrm{Y} 100} \mathrm{~V}_{\mathrm{H}}$ contribute to sequence-specific binding through base-specific hydrogen bonds, electrostatic interactions, and base stacking. ${ }^{20,21,35}$ These contacts are accessible to arginine and tyrosine side chains and have been observed in a range of protein॰nucleic acid systems. ${ }^{43-47}$ The effects of amino acid changes acquired through somatic mutation, on thermodynamic and kinetic parameters for DNA binding, were evaluated with reversion mutants. Unlike the other experiments completed with whole mAbs, recombi- nant single-chain 11F8 was used for all reversion mutant studies. We have previously shown that the affinity, specificity, thermodynamics, and kinetics of binding by single-chain $11 \mathrm{~F} 8$ are consistent with $11 \mathrm{~F} 8 .{ }^{20,22} \mathrm{R}^{\mathrm{B} 1} \mathrm{~V}_{\mathrm{H}}$ and ${ }^{\mathrm{Y} 100} \mathrm{~V}_{\mathrm{H}}$ in $11 \mathrm{~F} 8$ were selected for reversion mutation to mimic ${ }^{\mathrm{S} 31} \mathrm{~V}_{\mathrm{H}}$ and ${ }^{\mathrm{F} 100} \mathrm{~V}_{\mathrm{H}}$ of $9 \mathrm{~F} 11$ and $15 \mathrm{~B} 10$. The serine $\left({ }^{\mathrm{R} 31 \mathrm{~S}} \mathrm{~V}_{\mathrm{H}}\right)$ and phenylalanine $\left({ }^{\mathrm{Y} 100 \mathrm{~F}} \mathrm{~V}_{\mathrm{H}}\right)$ mutants as well as the double mutant $\left({ }^{\mathrm{R} 31 \mathrm{SY} 100 \mathrm{~F}} \mathrm{~V}_{\mathrm{H}}\right)$ were constructed via site-directed mutagenesis of single-chain $11 \mathrm{~F} 8$.

Analysis of the thermodynamic and kinetic parameters for the reversion mutants is predicated on the assumption that sequence differences between these antibodies are localized to the mutated residue. ${ }^{48}$ However, changes in DNA binding properties could also result from a loss of intramolecular interactions with adjacent protein residues, rather than from loss of interactions with ligand. ${ }^{49}$ Such intramolecular interactions can be detected by studying the double mutant to determine if the effects of the two mutations are additive (noncooperative) or not (suggest intramolecular interactions). ${ }^{50-53}$ Double mutant cycles for mutations to ${ }^{\mathrm{R} 31} \mathrm{~V}_{\mathrm{H}}$ and ${ }^{\mathrm{Y} 100} \mathrm{~V}_{\mathrm{H}}$, among other $11 \mathrm{~F} 8$ binding site residues, reveal that very little cooperativity exists between residues of 11F8 and suggest that interactions between residues in the complementarity determining region (CDRs) do not significantly contribute to binding. ${ }^{20}$

The affinity of ${ }^{\mathrm{Y} 100 \mathrm{~F}} \mathrm{~V}_{\mathrm{H}}$ for $\mathbf{1}$ is higher than that of $11 \mathrm{~F} 8$ (Table V). The likely source of higher affinity in the ${ }^{\mathrm{Y} 100 \mathrm{~F}} \mathrm{~V}_{\mathrm{H}} \bullet \mathbf{1}$ complex is a large decrease in unfavorable entropy change during recognition. Since affinity increases in the absence of the tyrosine hydroxyl group, we conclude that while an energetically stabilizing hydrogen bond may form between the ${ }^{\mathrm{Y} 100} \mathrm{~V}_{\mathrm{H}}$ hydroxyl and DNA, this interaction does not provide a significant driving force for $11 \mathrm{~F} 8 \bullet \mathbf{1}$ binding. Larger changes in affinity are observed in the ${ }^{\mathrm{R} 31 \mathrm{~S}} \mathrm{~V}_{\mathrm{H}} \bullet \mathbf{1}$ reversion mutant complex. ${ }^{\mathrm{R} 31 \mathrm{~S}} \mathrm{~V}_{\mathrm{H}} \bullet \mathbf{1}$ recognition occurs with a more favorable enthalpy change and a less favorable entropy change than $11 \mathrm{~F} 8 \bullet 1$, which collectively results in lower affinity. Thermodynamic data suggest that absence of arginine at ${ }^{31} \mathrm{~V}_{\mathrm{H}}$ affects the mode of recognition by altering both entropic and enthalpic interactions at the binding site. Similar to the thermodynamic parameters for whole mAbs 9F11 and 15B10, the 11F8 double mutant has $\sim 6$-fold lower affinity for 1. Because of uncertainty in the measured enthalpy and entropy it is not possible to ascribe the source of the weaker affinities to processes that are either primarily entropic or enthalpic. Somatic mutation to arginine, ${ }^{\mathrm{S} 31 \mathrm{R}} \mathrm{V}_{\mathrm{H}}$, seems to be a structural switch whereby $11 \mathrm{~F} 8$ can take advantage of different binding site contacts to recognize ssDNA differently than other mAbs originating from the same B-cell. 
Table V Thermodynamic Parameters for Reversion Mutant 1 Complexes

\begin{tabular}{lcccccc}
\hline $\mathrm{mAb}$ & \multicolumn{1}{c}{$\begin{array}{c}\Delta G \\
\left(\mathrm{kcal} \mathrm{mol}^{-1}\right)^{\mathrm{b}}\end{array}$} & $\begin{array}{c}\Delta H \\
\left(\mathrm{kcal} \mathrm{mol}^{-1}\right)^{\mathrm{b}}\end{array}$ & $\begin{array}{c}T \Delta S \\
\left(\mathrm{kcal} \mathrm{mol}^{-1}\right)^{\mathrm{b}}\end{array}$ & $-S K_{\text {obs }}{ }^{\mathrm{c}}$ & $\begin{array}{c}\Delta G_{\text {elect }} \\
\left(\mathrm{kcal} \mathrm{mol}^{-1}\right)^{\mathrm{d}}\end{array}$ \\
\hline $11 \mathrm{~F} 8$ & $9.5 \pm 0.6$ & $-11.0 \pm 0.4$ & $-17.1 \pm 2.0$ & $-6.3 \pm 1.0$ & $2.3 \pm 0.2$ & $-2.6 \pm 0.2$ \\
${ }_{\mathrm{Y} 100 \mathrm{~F}} \mathrm{~V}_{\mathrm{H}}$ & $5.3 \pm 0.3$ & $-11.4 \pm 0.2$ & $-12.0 \pm 2.0$ & $-0.6 \pm 0.1$ & $1.3 \pm 0.1$ & $-1.4 \pm 0.1$ \\
${ }^{\mathrm{R} 315} \mathrm{~V}_{\mathrm{H}}$ & $286.2 \pm 11$ & $-8.9 \pm 0.4$ & $-26.3 \pm 0.6$ & $-17.4 \pm 0.4$ & $1.4 \pm 0.1$ & $-1.6 \pm 0.1$ \\
${ }_{\mathrm{R} 31 \mathrm{SY} 100 \mathrm{~F}} \mathrm{~V}_{\mathrm{H}}$ & $61.8 \pm 1.4$ & $-9.9 \pm 0.8$ & $-15.6 \pm 0.6$ & $-5.8 \pm 0.2$ & $1.7 \pm 0.1$ & $-1.9 \pm 0.1$ \\
\hline
\end{tabular}

These data were acquired using recombinant single-chain 11F8. Refer to Table I for footnote definitions except for the following modifications.

$\mathrm{b}$ Thermodynamic parameters for ${ }^{\mathrm{R} 31 \mathrm{~S}} 11 \mathrm{~F} 8$ and ${ }^{\mathrm{R} 31 \mathrm{SY} 100 \mathrm{~F}} 11 \mathrm{~F} 8$ were determined assuming a zero heat capacity change due to linearity of the van't Hoff plot and thermodynamic parameters for ${ }^{\mathrm{Y} 100 \mathrm{~F}} 11 \mathrm{~F} 8$ were determined assuming a constant negative heat capacity suggested by curvature in the van't Hoff plot.

${ }^{\mathrm{c}}$ The stochiometry of salt release was determined with buffer salt concentrations ranging from $85-300 \mathrm{~m} M$.

Rate constants for ${ }^{\mathrm{Y} 100 \mathrm{~F}} \mathrm{~V}_{\mathrm{H}}$ binding to 1 reveal that the effect of tyrosine to phenylalanine mutation is small (Table $\mathrm{VI}) .{ }^{\mathrm{Y} 100 \mathrm{~F}} \mathrm{~V}_{\mathrm{H}}$ had little impact on the independent rate constants having values within error of $11 \mathrm{~F} 8 \bullet 1$. Previous studies showed the nonconservative mutation ${ }^{\mathrm{Y} 100 \mathrm{~A}} \mathrm{~V}_{\mathrm{H}}$ abrogated sequence specificity while ${ }^{\mathrm{Y} 100 \mathrm{~F}} \mathrm{~V}_{\mathrm{H}}$ retained sequence specificity. ${ }^{20}$ The aromatic moiety at position ${ }^{100} \mathrm{~V}_{\mathrm{H}}$ likely contributes to the favorable binding energy in the same way and to the same extent in all three mAbs.

If the differences in individual rate constants are not due to ${ }^{\mathrm{Y} 100 \mathrm{~F}} \mathrm{~V}_{\mathrm{H}}$, they likely result from ${ }^{\mathrm{R} 31 \mathrm{~S}} \mathrm{~V}_{\mathrm{H}}$. Previous studies showed that any change to ${ }^{\mathrm{R} 31} \mathrm{~V}_{\mathrm{H}}$ in $11 \mathrm{~F} 8$ abrogated sequence specificity. ${ }^{20}$ The kinetic parameters for ${ }^{\mathrm{R} 31 \mathrm{~S}} \mathrm{~V}_{\mathrm{H}}$ and the double mutant resembled $9 \mathrm{~F} 11$ and $15 \mathrm{~B} 10$ binding to 1 rather than 11F8. Each of the mutants exhibited a single exponential decrease in fluorescence upon binding that was slow and independent of [1]. The lack of an observed encounter complex coupled with a slow rate of formation and fast dissociation of the final complex was consistent with our expectations that side chain interactions between ${ }^{\mathrm{R} 31} \mathrm{~V}_{\mathrm{H}}$ and $\mathbf{1}$ are sufficient to control the mechanism of sequence-specific binding by $11 \mathrm{~F} 8$.

There could be two explanations for the single observed quench in tryptophan fluorescence that are consistent with our experimental observations. First, in the absence of cati- onic residues at the binding site, the rate of formation of the bimolecular encounter complex could slow such that it is indistinguishable from the rate of formation of the high affinity complex. Second, an encounter complex forms with a rate different from the rate of formation of the high affinity complex, but it cannot be detected by these methods. We have found that removing cationic character at the binding site through single conservative mutations that do not abrogate specific contacts $\left({ }^{\mathrm{R} 24 \mathrm{Q}} \mathrm{V}_{\mathrm{L}},{ }^{\mathrm{K} 52 \mathrm{Q}} \mathrm{V}_{\mathrm{L}},{ }^{\mathrm{K} 62 \mathrm{Q}} \mathrm{V}_{\mathrm{H}},{ }^{\mathrm{K} 64 \mathrm{Q}} \mathrm{V}_{\mathrm{H}}\right)$ and even removal of one of the two salt bridges $\left({ }^{\mathrm{R} 98 \mathrm{~K}} \mathrm{~V}_{\mathrm{H}}\right)$ results in slower, albeight detectable, association to form the encounter complex. ${ }^{24}$ It was surprising that mutagenesis of a single binding site charged residue at ${ }^{31} \mathrm{~V}_{\mathrm{H}}$ rendered $k_{1}$ undetectable because experimental conditions were tailored to capture the extremely fast encounter complex formation $\left(k_{1}\right)$ during $11 \mathrm{~F} 8 \bullet 1$ association. ${ }^{24}$ It stands to reason that a slower association rate to form the encounter complex should be detectable.

Previous mutagenesis studies showed that a single decrease in fluorescence independent of [DNA] was also observed for the ${ }^{\mathrm{W} 33 \mathrm{~F}} \mathrm{~V}_{\mathrm{H}}$ mutant in which minimal difference in binding affinity was observed with respect to wild-type $11 \mathrm{~F} 8 \bullet 1\left(0.45 \pm 0.1 \mathrm{nM}\right.$ and $0.31 \pm 0.1 \mathrm{nM}$, respectively) ${ }^{24} \mathrm{It}$ is possible that the signal change associated with $k_{1}$ originates from ${ }^{\mathrm{W}}{ }^{33} \mathrm{~V}_{\mathrm{H}}$. This residue lies within the DNA binding

Table VI Kinetic Parameters for 11F8 Reversion Mutant Recognition of 1

\begin{tabular}{lccccc}
\hline Protein & $k_{1}\left(\mu M^{-1} \mathrm{~s}^{-1}\right)$ & $k_{-1}\left(\mathrm{~s}^{-1}\right)$ & $k_{2}\left(\mathrm{~s}^{-1}\right)$ & $k_{-2}\left(\mathrm{~s}^{-1}\right)$ & $K_{\mathrm{d}}(\mathrm{n} M)$ \\
\hline${ }^{11 \mathrm{~F} 8}$ & $5.9 \pm 0.6$ & $13.5 \pm 1.4$ & $6.4 \pm 0.3$ & $7.5 \times 10^{-4} \pm 6 \times 10^{-5}$ & $0.3 \pm 0.1$ \\
${ }_{\mathrm{Y} 100 \mathrm{~F}} \mathrm{~V}_{\mathrm{H}}$ & $5.9 \pm 0.5$ & $13.3 \pm 1.1$ & $5.6 \pm 0.6$ & $8.5 \times 10^{-4} \pm 1 \times 10^{-5}$ & $0.3 \pm 0.1$ \\
${ }^{\mathrm{R} 315} \mathrm{~V}_{\mathrm{H}}$ & $\mathrm{NO}$ & $\mathrm{NO}$ & $1.4 \pm 0.2$ & $4.5 \times 10^{-3} \pm 2 \times 10^{-4}$ & $5.2 \pm 1.5$ \\
${ }^{\mathrm{R} 31 \mathrm{SY} 100 \mathrm{~F}} \mathrm{~V}_{\mathrm{H}}$ & $\mathrm{NO}$ & $\mathrm{NO}$ & $1.2 \pm 0.2$ & $1.5 \times 10^{-3} \pm 9 \times 10^{-4}$ & $6.3 \pm 1.3$ \\
\hline
\end{tabular}

Refer to Table IV for footnote definitions and description of independent rates upon DNA concentration. 
pocket and would be susceptible to small changes in its environment as the DNA approaches the binding site. Modeling studies suggest that ${ }^{\mathrm{W} 33} \mathrm{~V}_{\mathrm{H}}$ forms more extensive stacking interactions with ${ }^{\mathrm{T} 10} \mathbf{1}$ in the $11 \mathrm{~F} 8 \bullet \mathbf{1}$ complex than in the corresponding ${ }^{\mathrm{R} 31 \mathrm{~S}} 11 \mathrm{~F} 8 \bullet 1$ complex where ${ }^{\mathrm{W} 33} \mathrm{~V}_{\mathrm{H}}$ is minimally involved in stacking. ${ }^{35}$ Modeling data support the lack of an observed encounter complex for ${ }^{\mathrm{R} 31} \mathrm{~V}_{\mathrm{H}}$ mutants by suggesting that sufficient conformational change to cause a fluorescent response may not occur at ${ }^{\mathrm{W} 33} \mathrm{~V}_{\mathrm{H}}$ when the encounter complex forms.

\section{DISCUSSION}

Cationic residues, such as arginine attract, orient, and stabilize oppositely charged ligands within protein-binding

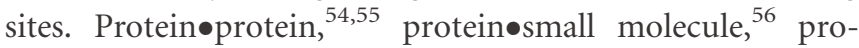
tein॰nucleic acid, ${ }^{57-59}$ and enzyme $\bullet$ substrate ${ }^{60}$ complexes all demonstrate that arginine residues at the binding site are involved in ligand recognition through electrostatic interactions and the propensity to form both salt bridge and bidentate hydrogen bonds. Basic side chains, arginine in particular, mediate association rates for mAb•antigen complexes, such as Y0101•VEGF, where affinity was enhanced 4 -fold through $k_{\text {on }}$ by incorporating an arginine residue at the periphery of the binding site with mutagenesis. ${ }^{61}$

Recent studies suggest an accumulation of arginine, lysine, and asparagine residues in CDRs of high affinity anti-DNA antibodies arise from somatic mutation of germline sequences. ${ }^{62,63}$ For example, a single somatic mutation to arginine in LCDR1 (first CDR in the light chain) of mAb B3 alters DNA and histone binding properties, and may mediate pathogenicity in SCID mice. ${ }^{62}$ Because of their involvement in antigen binding, heavy chain sequences, particularly HCDR1 and HCDR2, are most extensively mutated to improve DNA binding. ${ }^{64,65}$ HCDR2 of anti-dsDNA antibody $3 \mathrm{H} 9$ contains three somatic mutations, one being to arginine at position ${ }^{53} \mathrm{~V}_{\mathrm{H}}$. Reversion of arginine to the germline glycine abolished dsDNA binding while reversion of the other two somatic mutations had no effect on DNA binding. ${ }^{66}$ These data suggest that both the nature and location of binding site mutation affect binding affinity. While ${ }^{31} \mathrm{~V}_{\mathrm{H}}$ is generally not prone to mutation in many mAbs, anti-DNA isolated from both human and mouse suggest that somatic mutation at ${ }^{31} \mathrm{~V}_{\mathrm{H}}$ is common and often contributes to DNA binding. ${ }^{11,67,68}$ However, in the three crystal structures of anti-DNA/RNA bearing high sequence resemblance and residue usage to 11F8 (DNA1, BV04-01, and Jel 103), no contacts between ${ }^{31} \mathrm{~V}_{\mathrm{H}}$ and nucleic acid residues were observed. ${ }^{30}$ Our data suggest that a mutation acquired during affinity maturation results in faster association, that together with specific salt bridge and hydrogen bond contacts, orient and stabilize an ensuing 11 F8•DNA complex. ${ }^{24,35}$

Not all lupus anti-DNA are pathogenic, and it is not clear if a correlation exists between pathogenicity and either affinity or recognition of a particular DNA antigen. 11F8 initiates kidney inflammation in vivo by binding to ssDNA adherant to the glomerular basement membrane in kidney tissue. ${ }^{13}$ Nonpathogenic mAbs 9F11 and 15B10, which differ at ${ }^{31} \mathrm{~V}_{\mathrm{H}}$ and ${ }^{100} \mathrm{~V}_{\mathrm{H}}$, dissociate from both 1 and $\mathrm{T} 7$ faster than $11 \mathrm{~F} 8$, despite higher affinities for T7. 11F8 has markedly slower dissociation rates than the other mAbs for both sequence-specific and nonspecific complexes. These data suggest that pathogenicity may be related to the stability of the final complex. Once formed these slower-dissociating $11 \mathrm{~F} 8 \bullet \mathrm{DNA}$ complexes could remain bound to glomerular DNA antigens longer than nonpathogenic anti-DNA, permitting a more potent initiation of an inflammatory response.

\section{REFERENCES}

1. Routsias, J. G.; Vlachoyiannopoulos, P. G.; Tzioufas, A. G. Crit Rev Clin Lab Sci 2006, 43, 203-248.

2. Alba, P.; Bento, L.; Cuadrado, M. J.; Karim, Y.; Tungekar, M. F.; Abbs, I.; Khamashta, M. A.; D'Cruz, D.; Hughes, G. R. V. Ann Rheum Dis 2003, 62, 556-560.

3. Reichlin, M.; Wolfson-Reichlin, M. Clin Immunol 2003, 108, 69-72.

4. Ben-Chetrit, E.; Eilat, D.; Ben-Sasson, S. A. Immunology 1988, 65, 479-485.

5. Waer, M. Clin Rheumatol 1990, 9 (1, Suppl 1), 111-114.

6. Isenberg, D. A.; Ehrenstein, M. R.; Longhurst, C.; Kalsi, J. K.Arthritis Rheum 1994, 37, 169-180.

7. Ravirajan, C. T.; Rowse, L.; MacGowan, J. R.; Isenberg, D. A. Rheumatology 2001, 40, 1405-1412.

8. Koffler, D.; Carr, D.; Agnello, V.; Thiburn, R.; Kunkel, H. G. J Exp Med 1971, 134, 294-312.

9. Tsao, B. P.; Ebling, F. M.; Roman, C.; Panisian-Sahakian, N.; Calame, K.; Hahn, B. H. J Clin Invest 1990, 85, 530-540.

10. Foster, M. H.; Cizman, B.; Madaio, M. P. Lab Invest 1993, 69, 494-507.

11. Katz, J. B.; Limpanasithikul, W.; Diamond, B. J Exp Med 1994, 180, 925-932.

12. Ravirajan, C. T.; Rahman, M. A.; Papadaki, L.; Griffiths, M. H.; Kalsi, J. K.; Martin, A. C. R.; Ehrenstein, M. R.; Latchman, D. S.; Isenberg, D. A. Eur J Immunol 1998, 28, 339-350.

13. Swanson, P. C.; Yung, R. L.; Blatt, N. B.; Eagen, M. A.; Norris, J. M.; Richardson, B. C.; Johnson, K. J.; Glick, G. D. J Clin Invest 1996, 97, 1748-1760.

14. Swanson, P. C.; Ackroyd, P. C.; Glick, G. D. Biochemistry 1996, $35,1624-1633$.

15. Stevens, S. Y.; Glick, G. D. Biochemistry 1999, 38, 560-568.

16. Maizels, N. Annu Rev Genet 2005, 39, 23-46.

17. Odegard, V. H.; Schatz, D. G. Nat Rev Immunol 2006, 8, 573-583.

18. Kabat, E. A.; Wu, T. T.; Bilofsky, H. J Biol Chem 1977, 252, 6609-6616. 
19. Blatt, N. B.; Bill, R. M.; Glick, G. D. Hybridoma 1998, 17, 33 39.

20. Cleary, J.; Glick, G. D. Biochemistry 2003, 42, 30-41.

21. Ackroyd, P. C.; Cleary, J.; Glick, G. D. Biochemistry 2001, 40, 2911-2922.

22. Beckingham, J. A.; Glick, G. D. Bioorg Med Chem 2001, 9, 2243-2252.

23. Mach, H.; Middaugh, C. R.; Lewis, R. V. Anal Biochem 1992, 200, 74-80.

24. Beckingham, J. A.; Cleary, J.; Bobeck, M.; Glick, G. D. Biochemistry 2003, 42, 4118-4126.

25. Lee, J. S.; Dombroski, D. F.; Mosmann, T. R. Biochemistry 1982, 21, 4940-4945.

26. Tan, E. M. Adv Immunol 1989, 44, 93-151.

27. Rumbley, C. A.; Denzin, L. K.; Yantz, L.; S. Y., T.; Voss, E. W., Jr. J Biol Chem 1993, 268, 13667-13674.

28. Komissarov, A. A.; Calcutt, M. J.; Marchbank, M. T.; Peletskaya, E. N.; Deutscher, S. L. J Biol Chem 1996, 271, 12241-12246.

29. Yokoyama, H.; Mizutani, R.; Satow, Y.; Komatsu, Y.; Ohtsuka, E.; Nikaido, O. J Mol Biol 2000, 299, 711-723.

30. Tanner, J. J.; Komissarov, A. A.; Deutscher, S. L. J Mol Biol 2001, 314, 807-822.

31. Record, M. T. J.; Lohman, T. M.; deHaseth, P. J Mol Biol 1976, 107, 145-158.

32. Record, M. T. J.; Spolar, R. S. In The Biology of Nonspecific DNA-Protein Interactions; Revzin, A., Ed.; CRC Press: Boca Raton, FL, 1990; pp 33-69.

33. Record, M. T. J.; Ha, J. H.; Fisher, M. A. Methods Enzymol 1991, 208, 291-343.

34. Winzor, D. J.; Jackson, C. M. J Mol Recognit 2006, 19, 389-407.

35. Bobeck, M.; Rueda, D.; Walter, N. G.; Glick, G. D. Has been submitted to Biochemistry 1/29/07.

36. Dang, H.; Harbeck, R. J. J Lab Clin Med 1982, 9, 139-145.

37. Mascotti, D. P.; Lohman, T. M. Biochemistry 1997, 36, 72727279.

38. Draper, D. E. Proc Natl Acad Sci USA 1993, 90, 7429-7430.

39. Jian, S.; Viadiu, H.; Aggarwal, A. K.; Weinstein, H. Biophys J 2003, 84, 3317-3325.

40. Frank, D. E.; Saecker, R. M.; Bond, J. P.; Capp, M. W.; Tsodikov, O. V.; Melcher, S. E.; Levandoski, M. M.; Record, M. T. J. J Mol Biol 1997, 267, 1186-1206.

41. Selzer, T.; Albeck, S.; Schreiber, G. Nat Struct Biol 2000, 7, 537541.

42. Kiel, C.; Selzer, T.; Shaul, Y.; Schreiber, G.; Herrmann, C. Proc Natl Acad Sci USA 2004, 101, 9223-9228.

43. Wilkinson, T. A.; Botuyan, M. V.; Kaplan, B. E.; Rossi, J. J.; Chen, Y. J Mol Biol 2000, 303, 515-529.

44. Luscombe, N. M.; Austin, S. E.; Barman, H. M.; Thorton, J. M. Genome Biol 2000, 1, 1-37.
45. Liu, Y.; Yang, Z.; Utzat, C. D.; Liu, Y.; Geacintov, N. E.; Basu, A. K.; Zou, Y. Biochem J 2005, 385, 519-526.

46. Wojciechowski, M.; Fogolari, F.; Baginski, M. J Struct Biol 2005, 152, 169-184.

47. Larkin, C.; Datta, S.; Harley, M. J.; Anderson, B. J.; Ebie, A.; Hargreaves, V.; Schildbach, J. F. Structure 2005, 10, 1533-1544.

48. Mildvan, A. S.; Weber, D. J.; Kuliopulos, A. Arch Biochem Biphys 1992, 294, 327-340.

49. Di Cera, E. Adv Protein Chem 1998, 51, 59-119.

50. Carter, P. J.; Winter, G.; Wilkinson, A. J.; Fersht, A. R. Cell 1984 38, 835-840.

51. Wells, J. A. Biochemistry 1990, 29, 8509-8517.

52. Ackers, G. K.; Smith, F. R. Annu Rev Biochem 1985, 54, 597629.

53. Horovitz, A.; Bochkareva, E. S.; Yifrach, O.; Girshovich, A. S. J Mol Biol 1994, 238, 133-138.

54. Cohen, G. H.; Sheriff, S.; Davies, D. R. Acta Crystallogr D 1996, $52,315-326$.

55. Wang, T.; Tomic, S.; Gabdoulline, R. R.; Wade, R. C. Biophys J 2004, 87, 1618-1630.

56. Huang, H.-C.; Briggs, J. M. Biopolymers 2001, 63, 247-260.

57. Katsamba, P. S.; Myszka, D. G.; Laird-Offringa, I. A. J Biol Chem 2001, 276, 21476-21481.

58. Guth, A. M.; Zhang, X.; Smith, D.; Detanico, T.; Wysocki, L. J. J Immunol 2003, 171, 6260-6266.

59. Mitton-Fry, R. M.; Anderson, E. A.; Theobald, D. L.; Glustrom, L. W.; Wuttke, D. S. J Mol Biol 2004, 338, 241-255.

60. Livesay, D. R.; Jambeck, P.; Rojnuckarin, A.; Subramaniam, S. Biochemistry 2003, 42, 3464-3473.

61. Marvin, J. S.; Lowman, H. B. Biochemistry 2003, 42, 70777083.

62. Rahman, A. Rheumatology 2004, 43, 1326-1336.

63. Jang, Y. J.; Stollar, B. D. Cell Mol Life Sci 2003, 60, 309-320.

64. Rahman, A.; Giles, I.; Haley, J.; Isenberg, D. A. Lupus 2002, 11, 807-823.

65. Behrendt, M.; Partridge, L. J.; Griffiths, B.; Goodfield, M.; Snaith, M.; Lindsey, N. J. Clin Exp Immunol 2003, 131, 182189.

66. Haley, J.; Mason, L. J.; Nagl, S.; Giles, I.; Latchman, D. S.; Isenberg, D. A.; Rahman, A. Mol Immunol 2004, 40, 745-758.

67. Seal, S. N.; Hoet, R. M. A.; Raats, J. M. H.; Radic, M. Z. Arthritis Rheum 2000, 43, 2132-2138.

68. Livesay, D. R.; Subramaniam, S. Protein Eng Des Sel 2004, 17, 463-472.

Reviewing Editor: Kenneth Breslauer 